\begin{abstract}
CONF- $9606116--88$ ANL/EA/CP- -91114

NATIONAL IGNITION FACILITY: IMPACTS OF CHEMICAL ACCIDENTS AND COMPARISON OF CHEMICAL AND RADIOLOGICAL ACCIDENT APPROACHES
\end{abstract}

Michael A. Lazaro, Anthony J. Policastro, and Mark F. Rhodes Argonne National Laboratory

Environmental Assessment Division

9700 South Cass Avenue

Argonne, Illinois 60439

\section{"AEIVED \\ MnU 211996 \\ OSTI}

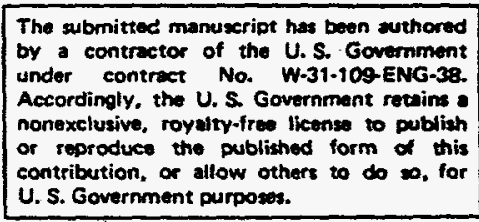

The submitted manuxeript has been suthored

oy a contractor of the U.S. Government

hed form of this

U.S. Government purposes. 


\section{DISCLAIMER}

This report was prepared as an account of work sponsored by an agency of the United States Government. Neither the United States Government nor any agency thereof, nor any of their employees, makes any warranty, express or implied, or assumes any legal liability or responsibility for the accuracy, completeness, or usefulness of any information, apparatus, product, or process disclosed, or represents that its use would not infringe privately owned rights. Reference herein to any specific commercial product, process, or service by trade name, trademark, manufacturer, or otherwise does not necessarily constitute or imply its endorsement, recommendation, or favoring by the United States Government or any agency thereof. The views and opinions of authors expressed herein do not necessarily state or reflect those of the United States Government or any agency thereof. 


\section{DISCLAMMER}

Portions of this document may be illegible in electronic image products. Images are produced from the best available original document. 


\title{
NATIONAL IGNITION FACILITY: IMPACTS OF CHEMICAL ACCIDENTS AND COMPARISOY OF CHEMICAL AND RADIOLOGICAL ACCIDENT APPROACHES
}

\author{
Michael A. Lazaro, Anthony J. Policastro, and Mark F. Rhodes \\ Argonne National Laboratory \\ Environmental Assessment Division \\ 9700 South Cass Avenue \\ Argonne, Illinois 60439
}

\section{ABSTRACT}

An environmental assessment was conducted to estimate potential impacts or consequences associated with constructing and operating the proposed National Ignition Facility (NIF). The multidisciplinary assessment covered topics ranging from radiological and chemical health and safety to socioeconomic and land-use issues. The impacts of five chemical accidents that could occur at NIF are compared, and the extent of their consequences for workers and off-site populations are discussed. Each of the five accident scenarios was modeled by a chemical release and dispersion model with a toxicological criterion for evaluating potential irreversible human health effects. Results show that most of the chemical release scenarios considered will not impair the general public in taking protective actions in the event of an accidental release. The two exceptions are the mercury release (equipment failure) scenarios for the conceptual design and the enhanced design. In general, the predicted maximum threat zones are significantly less than the distance to the point of nearest public access.

\section{INTRODUCTION}

The U.S. Department of Energy (DOE) has proposed the construction and operation of a National Ignition Facility (NIF) to achieve fusion ignition in the laboratory. Five candidate locations at four DOE sites are being considered for the facility. The preferred location is Lawrence Livermore National Laboratory (LLNL) in Livermore, Califomia. The other candidate locations are Los Alamos National Laboratory (LANL), Sandia National Laboratories (SNL), the Nevada Test Site (NTS), and the North Las Vegas Facility (NLVF). In evaluating the five locations, it is necessary to compare the impacts of nonradiological accidental releases among the sites.' This paper considers five nonradiological accident release scenarios for the conceptual design and the enhanced design at the five candidate sites (Table 1). In addition, the approaches for nonradiological accident modeling and radiological accident modeling are compared.

For each of the five candidate locations, health effects on both workers and the general public must be considered for each nonradiological accident scenario. To predict health effects in both populations, it is necessary to identify chemicals of concern at each candidate facility, accident scenarios that could cause the release of these chemicals, and the probability of the occurrence of such accidents.

\section{CHEMICAL ACCIDENT SCENARIOS}

Five chemicals and five associated accident scenarios were identified and modeled for four candidate locations. Table 2 summarizes the chemical accident release scenarios. Chemical inventories for both the conceptual design and the enhanced design were examined to determine which chemicals are toxic and could cause toxic inhalation effects. In general, the NIF would maintain large inventories of low-hazardclassification or low-exposure-criteria materials. Most chemicals were eliminated from consideration on the basis of a joint weighting of those two factors. The five chemicals identified for consequence modeling were mercury, carbonyl fluoride, hydrogen fluoride, alumina, and silica. For NTS, a propane tank failure accident scenario was also modeled because propane is used for backup utility service for boilers and heaters.

\section{EVALUATION METHODOLOGY}

Many consequence models are available for predicting the effects of a chemical accident. The choice of a particular model depends on the characteristics of the release scenario, scale of the problem, level of data available for input, and level of accuracy required. The greater the desired accuracy, the more detailed the model inputs must be. The two models selected for the NIF project were Areal Locations of Hazardous Atmospheres ${ }^{2}$ (ALOHA) and FIREPLUME. ${ }^{3}$ 
TABLE 1 Accident Scenarios

\begin{tabular}{ll}
\hline \multicolumn{1}{c}{ Initiator } & \multicolumn{1}{c}{ Release/Source } \\
\hline Equipment tailure & Mercury release from ignitron switches \\
Earthquake & Combined release of alumina and silica from the target chamber \\
In-facility fire & Carbonyl fluoride release from the optics treatment area \\
In-facility fire & Hydrogen fluoride release from the optics treatment area \\
Aircraft crash/fire & Mercury release from ignitron switches \\
Tank failure & Propane gas leak (modeled for NTS) \\
\hline
\end{tabular}

The ALOHA model uses a Gaussian-type dispersion approach to describe the movement and the spread of a neutrally buoyant gas and a heavy-gas dispersion model to describe the movement and spread of a dense gas. The ALOHA model estimates plume extent and concentrations for short-term chemical releases. It is commonly used in conjunction with the appropriate health criteria for emergency response planning. It does not consider topography.

The FIREPLUME model consists of two components: a Monte Carlo code that estimates the dispersion of both buoyant and nonbuoyant chemical releases in the atmospheric boundary layer and a puff dispersion code based in part on a Monte Carlo code. The FIREPLUME model predicts ground-level concentrations resulting from the release of a hazardous material within an instantaneously discharged thermal (i.e., a fireball), a fire, or a smoldering fire before it is fully extinguished. The FIREPLUME model was used to simulate the release of mercury from the ignitron switches resulting from an aircraft accident and subsequent fire at the NIF site.

Several bounding conditions were identified for meteorology. For five of the six cases, wind speed was assumed to be $1 \mathrm{~m} / \mathrm{s}(3.3 \mathrm{f} / \mathrm{s})$, with a stability class of $F$, extremely stable. Under these conditions and for these release types, "worst-case" dispersion and conservative impacts can be expected. For the aircraft crash and fire, the mercury release was modeled by using stability class $A$ and a wind speed of $2.0 \mathrm{~m} / \mathrm{s}$. For this release, these conditions yielded the most conservative impacts. Emergency Response Planning Guideline-2 (ERPG-2) values were chosen as the health criteria. ERPG-2 values are defined as "the maximum airborne concentration below which it is believed that nearly all individuals could be exposed for up to one hour without experiencing or developing ineversible or other serious health effects or symptoms that could impair an individual's ability to take protective action." Within the contour defined by the maximum threat zone (as predicted by the models), individuals who are outdoors would be exposed to concentrations that would impair their ability to take protective action. Outside the maximum threat zone, individuals should be able to take adequate protective action. Individuals who are within the maximum threat zone but are indoors would experience different concentrations from those who are outdoors.

ERPG-2 surrogate values were used whenever an ERPG-2 value had not yet been determined. For example, surrogate ERPG-2 values could be determined by multiplying the threshold limit value, time-weighted average for the chemical of concern by a weighting factor of 5 . For the combined alumina/silica accident release, the impacts of the exposure to both chemicals are combined (by weighting their associated health indices) to account for health effects associated with simultaneous downwind exposures. Five of the six cases involve releases at ground level. Mercury resulting from an equipment failure was modeled by assuming a release from the top of the building at a height of $17 \mathrm{~m}$.

\section{MODEL RESULTS}

Tables 3 through 6 present the modeling results for the mercury, alumina/silica, carbonyl fluoride and hydrogen fluoride chemical accident scenarios at each of the five candidate sites. Indoor and outdoor chemical concentrations were predicted with the ALOHA model. Distances predicted by the ALOHA and FIREPLUME models for the maximum threat zone are less than the distance to the nearest public access for all cases, except the equipment failure mercury release scenarios at NLVF and LLNL. Although atmospheric concentrations resulting from an accident would exceed the ERPG-2 values outdoors at the two facilities, workers who were indoors would be protected. Indoor concentrations depend on specific building ventilation rates. Details of each building within the threat zone are necessary for quantitative evaluation of indoor chemical concentrations. Typically, single-storied structures show concentrations of a factor of 5 or more below the outdoor levels. 
Table 3 presents the results of the modeling for the mercury release resulting from an aircraft crash and fire at the five candidate sites. Outdoor concentrations of mercury were predicted with the FIREPLUME model. Model results indicate negligible mercury concentrations for all distances from the site of the aircraft crash and fire. Predicted concentrations of mercury are significantly less than the ERPG-2 value, $0.125 \mathrm{mg} / \mathrm{m}^{3}$, for all distances from the accident site.

On the basis of results from the ALOHA and FIREPLUME models, most of the chemical accident scenarios considered will not impair the ability of a member of the general public to take protective action in the event of such an accident. The two exceptions are the equipment failure mercury release scenario for the conceptual design and the enhanced design at NLVF and LLNL. Figure 1 shows three accident release scenario plumes, simulated with the ALOHA model, superimposed over the proposed LLNL-NIF site map.

\section{COMPARISON OF CHEMICAL AND RADIOLOGICAL MODELING}

It is difficult to compare directly the results from chemical and radiological modeling because of differences in models and health endpoints. Radiological modeling predicts the probability of longterm cancer fatalities among the general public, while chemical dispersion modeling, as used for chemical accidents, predicts a "threat zone" on the basis of a single human health endpoint associated with acute

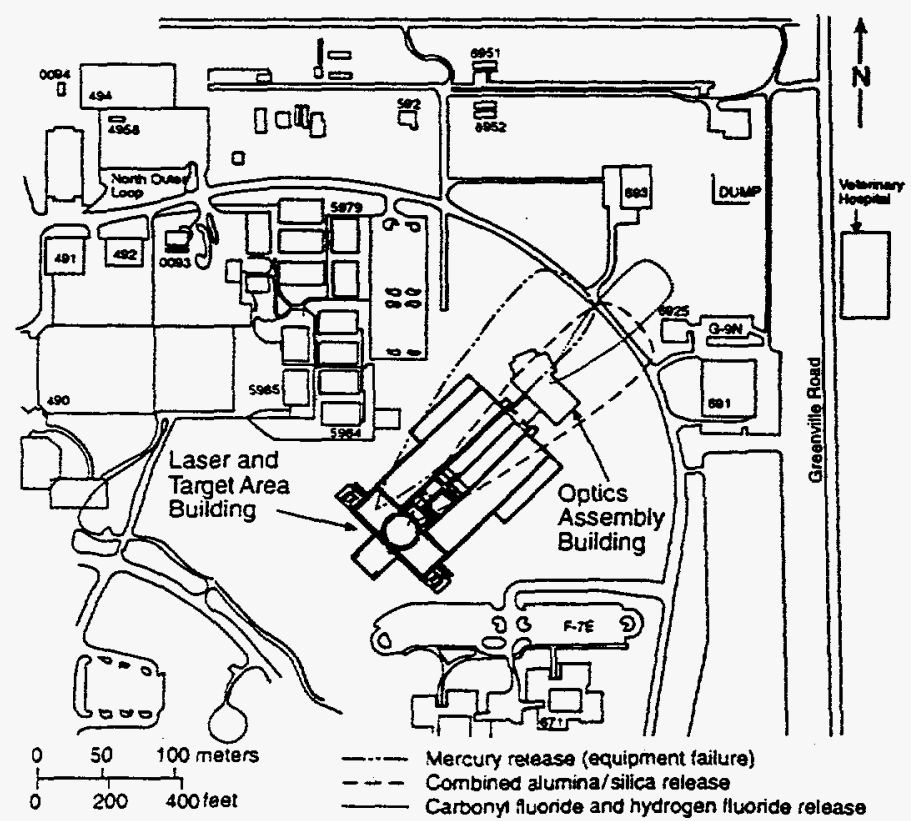

exposure to a chemical. The "endpoint" associated with radiological exposure is delayed; the "endpoint" associated with chemical exposure is immediate.

The GENII program ${ }^{4}$ was used to model radiation doses to workers and the general public at the five candidate sites. Radiation doses were converted to health effects on the basis of the 1990 recommendations of the International Commission on Radiological Protection. The results of that program led to predictions of radiation doses and cancer fatalities for a separate set of radiological accidents for the NIF. The results of the radiological accidents are presented in Ref. 5.

\section{CONCLUSIONS}

On the basis of the results of the chemical accident release modeling for the NIF facility, the NIF presents minimal chemical exposure hazard. The maximum threat zone for each nonradiological accident scenario examined is within the site boundaries of each proposed site. The two exceptions are the equipment failure scenario involving a mercury release for the conceptual design and the enhanced design at NLVF and LLNL. Chemical and radiological modeling results cannot be compared easily because of differences in models and health endpoints.

\section{ACKNOWLEDGMENTS}

This work was supported by the U.S. Department of Energy under contract W-31-109-ENG-38. This research was conducted as part of the DOE environmental impact statement for the Stockpile Stewardship Program. We appreciate the support of the DOE/Oakland Office and the efforts of Charles Taylor for support of this effort.

\section{REFERENCES}

1. DOE, 1996, Draft Programmatic Environmental Impact Statement for Stockpile Stewardship and Management, Volume III, U.S. Department of Energy, Washington, D.C.

2. Reynolds, M., 1992, ALOHA (Areal Locations of Hazardous Atmospheres) 5.0: Theoretical Description, National Oceanic and Atmospheric Administration, Seattle, Wash.

3. Brown, B.F., et al., 1996, unpublished information, Argonne National Laboratory, Argonne, Illinois.

FIGURE 1 Overlay of Three Chemical Accident

Plumes on the NIF Site at LLNL 
4. Napier, B.A., et al., 1988, GENII - The Hanford Environmental Radiation Dosimetry Software System, Vols. 1-3, Pacific Northwest Laboratory, Richland, Wash.

5. Hong, K., and M.A. Lazaro, 1996, Radiological Assessments for the National Ignition Facility, presented at American Nuclear Society Annual Meeting, Reno, Nevada, June 16-20.

6. Mishima, J., 1993, Recommend Values and Technical Bases for Airborne Release Fractions, Airborne Release Rates, and Respirable Fractions; Materials from Accidents in DOE Fuel Cycle, ExReactor Facilities, Rev. 3.
7. DOE, 1992, Hazard Classification and Accident Analysis Techniques for Compliance with DOE Order 5480.23, U.S. Department of Energy, Washington D.C.

8. Lazaro, M.A., et al., 1996, Technical Documentation in Support of the Draft ProjectSpecific Analysis for Construction and Operation of the National Ignition Facility, Argonne National Laboratory, Argonne, Illinois.

TABLE 2 Summary of Chemical Accident Release Scenarios for the National Ignition Facility

\begin{tabular}{|c|c|c|c|c|c|}
\hline Release Scenario & 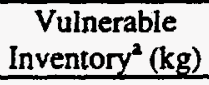 & $\begin{array}{l}\text { Release } \\
\text { Fraction } \\
\end{array}$ & $\begin{array}{l}\text { Total Quantity } \\
\text { Released (g) }\end{array}$ & $\begin{array}{l}\text { Release } \\
\text { Duration } \\
\end{array}$ & $\begin{array}{c}\text { Release } \\
\text { Height }\end{array}$ \\
\hline $\begin{array}{l}\text { Mercury } \\
\text { Equipment failure } \\
\text { Aircraft crash }\end{array}$ & $\begin{array}{r}6.5 \\
51.5\end{array}$ & $\begin{array}{c}1.0 \times 10^{-2^{b}} \\
1.0\end{array}$ & $\begin{array}{c}65 \\
51,500\end{array}$ & $\begin{array}{l}30 \mathrm{~min} \\
16 \mathrm{~min}\end{array}$ & $\begin{array}{c}17 \mathrm{~m} \\
\text { Grn. level }\end{array}$ \\
\hline Alumina & $\begin{array}{r}6.7 \\
(29.6)\end{array}$ & $1.0 \times 10^{-3^{6}}$ & $\begin{array}{l}6.7 \\
(29.6)\end{array}$ & $7.6 \mathrm{~min}^{\mathrm{d}}$ & Gm. level \\
\hline Silica & $\begin{array}{l}2.1 \\
(4.4)\end{array}$ & $1.0 \times 10^{-3^{e}}$ & $\begin{array}{c}2.1 \\
(4.4)\end{array}$ & $7.6 \mathrm{~min}^{\mathrm{d}}$ & Gm. level \\
\hline Hydrogen fluoride & $\begin{array}{c}273 \\
\text { fluorinert } \\
(151 \mathrm{~L}) \\
3 \mathrm{~kg} \text { Teflon }\end{array}$ & $\begin{array}{l}1.0 \times 10^{-4^{e}} \\
3.8 \times 10^{-1^{e}}\end{array}$ & 27.3 & $1 \mathrm{~h}$ & Grn. level \\
\hline Carbonyl fluoride & $3 \mathrm{~kg}$ Teflon & $3.8 \times 10^{-1}=$ & 1,890 & $1 \mathrm{~h}$ & Gm. level \\
\hline Propane & $56.780 \mathrm{~L}$ & 1.0 & $56,780 \mathrm{~L}$ & $1 \mathrm{~h}$ & Gm. level \\
\hline
\end{tabular}

2 Values are the same for conceptual design and the enhanced design except for vulnerable inventory and total quantity released for alumina and silica. Values in parentheses for those two materials are for the enhanced option.

Bef. 6

' Ref. 7

Corresponds to a wind speed of $1 \mathrm{~m} / \mathrm{s}$.

Ref. 8 
TABLE 3 Summary of Mercury Release Scenarios Predictions at the Five Candidate Sites"

\begin{tabular}{llccc}
\hline \multicolumn{1}{c}{ Site } & Nearest Public Access & $\begin{array}{c}\text { Concentration } \\
\text { Equipment Failure } \\
\text { Outdoor/Indoor } \\
\left(\mathrm{mg} / \mathrm{m}^{3}\right)\end{array}$ & $\begin{array}{c}\text { Concentration } \\
\text { Airplane Crash/Fire } \\
\left(\mathrm{mg}^{\mathrm{s}} \mathrm{m}^{3}\right)\end{array}$ & $\begin{array}{c}\text { Maximum Threat } \\
\text { Zone }{ }^{\mathrm{d}}(\mathrm{m})\end{array}$ \\
\hline LLNL & $245 \mathrm{~m} \mathrm{ENE}$ & $0.124 / 0.025$ & 237 \\
NTS & $20,000 \mathrm{~m} \mathrm{SSW}$ & Negligible & $2.47 \times 10^{-5}$ & 237 \\
NLVF & $210 \mathrm{~m} \mathrm{~W}$ & $0.165 / 0.033$ & $<10^{-5}$ & 239 \\
LANL & $1,620 \mathrm{~m} \mathrm{NNE}$ & Negligible & $<10^{-5}$ & 237 \\
SNL & $1,864 \mathrm{~m} \mathrm{~N}$ & $0.0204 / 0.0035$ & $<10^{-5}$ & 237 \\
\hline
\end{tabular}

a Results are the same for the conceptual design and the enhanced design.

The ALOHA model chooses a neutrally buoyant or a heavy-gas treatment for dispersion, depending on which modeling approach is most appropriate. The mercury release from the equipment failure was modeled as a heavy gas. The FIREPLUME model accounts for fire heat generation and simulates buoyant plume rise.

c Predicted concentrations at nearest point of public access.

d The maximum threat zone corresponds to the distance from the source beyond which concentrations are below the ERPG-2 value. Because of plume rise, the FIREPLUME-estimated concentrations did not exceed the equivalent ERPG-2 value for mercury.

TABLE 4 Summary of Alumina/Silicate Release Scenario Predictions at the Five Candidate Sites for the Conceptual Design and the Enhanced Design

\begin{tabular}{|c|c|c|c|c|}
\hline Site & Nearest Public Access & Dispersion Type ${ }^{2}$ & $\begin{array}{l}\text { Outdoor/Indoor } \\
\text { Concentration } \\
\left(\mathrm{mg} / \mathrm{m}^{3}\right)\end{array}$ & $\begin{array}{c}\text { Maximum Threat } \\
\text { Zone }^{c}(\mathrm{~m})\end{array}$ \\
\hline \multicolumn{5}{|c|}{ Conceptual Design } \\
\hline $\begin{array}{l}\text { LLNL } \\
\text { NTS } \\
\text { NLVF } \\
\text { LANL } \\
\text { SNL }\end{array}$ & $\begin{array}{l}800 \mathrm{~m} \mathrm{E} \\
20,000 \mathrm{~m} \mathrm{SSW} \\
210 \mathrm{~m} \mathrm{~W} \\
1,620 \mathrm{~m} \mathrm{NNE} \\
1,864 \mathrm{~m} \mathrm{~N}\end{array}$ & $\begin{array}{l}\text { Neutrally Buoyant } \\
\text { Neutrally buoyant } \\
\text { Neutrally buoyant } \\
\text { Neutrally buoyant } \\
\text { Neutrally buoyant }\end{array}$ & $\begin{array}{l}0.0509 / 0.0001 \\
\text { Negligible } \\
0.296 / 0.002 \\
\text { Negligible } \\
0.0123 / 0.0001\end{array}$ & $\begin{array}{l}171 \\
171 \\
171 \\
171 \\
174\end{array}$ \\
\hline \multicolumn{5}{|c|}{ Enhanced Design } \\
\hline LLNL & $800 \mathrm{mE}$ & Neutrally buoyant & $0.11 / 0.0017$ & 231 \\
\hline $\begin{array}{l}\text { NTS } \\
\text { NLVF } \\
\text { LANL } \\
\text { SNL }\end{array}$ & $\begin{array}{l}20,000 \mathrm{~m} \mathrm{SSW} \\
210 \mathrm{~m} \mathrm{~W} \\
1,620 \mathrm{~m} \mathrm{NNE} \\
1,864 \mathrm{~m} \mathrm{~N}\end{array}$ & $\begin{array}{l}\text { Neutrally buoyant } \\
\text { Neutrally buoyant } \\
\text { Neutrally buoyant } \\
\text { Neutrally buoyant }\end{array}$ & $\begin{array}{l}\text { Negligible } \\
\text { Negligible } \\
\text { Negligible } \\
0.0268 / 0.0001\end{array}$ & $\begin{array}{l}231 \\
231 \\
231 \\
234\end{array}$ \\
\hline
\end{tabular}

a The ALOHA model chooses a neutrally buoyant or a heavy-gas treatment for dispersion, depending on which modeling approach is most appropriate.

Predicted concentrations at nearest point of public access.

c Differences in predictions among the various sites (171 compared with $174 \mathrm{~m}$ or 231 compared with $234 \mathrm{~m}$ ) are not important and are due to the atmospheric differences (elevation) among the sites.

d The maximum threat zone corresponds to the distance from the source beyond which concentrations are below the ERPG-2 value. 
TABLE 5 Summary of Carbonyl Fluoride Release Scenario Predictions at the Five Candidate Sites for the Conceptual Design and the Enhanced Design

\begin{tabular}{lllcc}
\hline \multicolumn{1}{c}{ Site } & Nearest Public Access & $\begin{array}{c}\text { Dispersion } \\
\text { Type }^{b}\end{array}$ & $\begin{array}{c}\text { Outdoor/Indoor } \\
\text { Concentration } \\
\left(\mathrm{mg} / \mathrm{m}^{3}\right)\end{array}$ & $\begin{array}{c}\text { Maximum } \\
\text { Threat Zone (m) }\end{array}$ \\
\hline LLNL & $120 \mathrm{~m} \mathrm{ENE}$ & Heavy gas & $18.9 / 4.14$ & 99 \\
NTS & $20,000 \mathrm{~m} \mathrm{SSW}$ & Heavy gas & Negligible & 75 \\
NLVF & $210 \mathrm{~m} \mathrm{~W}$ & Heavy gas & $4.83 / 1.02$ & 75 \\
LANL & $1,620 \mathrm{~m} \mathrm{NNE}$ & Heavy gas & $0.198 / 0.0324$ & 70 \\
SNL & $1.864 \mathrm{~m} \mathrm{~N}$ & Heavy gas & $0.608 / 0.114$ & 70 \\
\hline
\end{tabular}

Identical accidents are proposed for the conceptual design and enhanced design, so no differences exist between these options.

- The ALOHA model chooses a neutrally buoyant or a heavy-gas treatment for dispersion, depending on which modeling approach is most appropriate.

c Predicted concentrations at nearest point of public access.

The maximum threat zone corresponds to the distance from the source beyond which concentrations are below the ERPG-2 value.

TABLE 6 Summary of Hydrogen Fluoride Release Scenario Predictions at the Five Candidate Sites for Conceptual Design and Enhanced Options

\begin{tabular}{|c|c|c|c|c|}
\hline Site & Nearest Public Access & Dispersion Type ${ }^{b}$ & $\begin{array}{l}\text { Outdoor/Indoor } \\
\text { Concentration } \\
\left(\mathrm{mg} / \mathrm{m}^{3}\right)\end{array}$ & $\begin{array}{l}\text { Maximum } \\
\text { Threat Zone } \\
\text { (m) }\end{array}$ \\
\hline LLNL & $120 \mathrm{~m} \mathrm{ENE}$ & Neutrally Buoyant & $11.2 / 4.66$ & 99 \\
\hline NTS & $20,000 \mathrm{~m} \mathrm{SSW}$ & Neutrally Buoyant & $<10^{-2} / 10^{-2}$ & 75 \\
\hline NLVF & $210 \mathrm{~m} \mathrm{~W}$ & Neutrally Buoyant & $3.98 / 1.54$ & 75 \\
\hline LANL & $1,620 \mathrm{~m} \mathrm{NNE}$ & Neutrally Buoyant & $0.095 / 0.027$ & 70 \\
\hline SNL & $1,864 \mathrm{~m} \mathrm{~N}$ & Neutrally Buoyant & $0.076 / 0.020$ & 70 \\
\hline
\end{tabular}

Identical accidents are proposed for the conceptual design and enhanced design, so no differences exist between these options.

${ }^{b}$ The ALOHA model chooses a neutrally buoyant or heavy-gas treatment for dispersion, depending on which modeling approach is most appropriate.

c Predicted concentrations at nearest point of public access.

The maximum threat zone corresponds to the distance from the source beyond which concentrations are below the ERPG-2 value. 